\title{
Demographics and microbiological profile of Pneumonia in United Arab Emirates
}

\author{
S. Al-Muhairi1, T. Zoubeidi2, M. Ellis'1, \\ M. Gary Nicholls ${ }^{1}$, W. Safa 3 , J. Joseph 1
}

ABSTRACT: Demographics and Microbiological Profile of Pneumonia in United Arab Emirates. S. Al-Muhairi, T. Zoubeidi, M. Ellis, M. Gary Nicholls, W. Safa, J. Joseph.

Background. Pneumonia is a common respiratory disease, which has a mortality rate of approximately $14 \%$ worldwide. The management of pneumonia is based on the patient and microbiological profile existing in the community. There is a paucity of data regarding patient demographics and the microbiological profile for pneumonia in the United Arab Emirates (UAE).

Methods. We conducted a retrospective analysis of inpatients with pneumonia in the UAE. Epidemiological, clinical and microbiological data was collected from patients over the age of 16 years admitted to a single university hospital with a diagnosis of pneumonia between the years 1997 and 2002. Patients were categorised as having community acquired (CAP) or hospital acquired pneumonia (HAP).

Results. Among the 361 patients, 186 were females and 175 males. The mean age $( \pm$ SEM $)$ of the males was $59 \pm 1.6$ years and of the females, $56.9 \pm 1.5$ years. The annual hospital admission rate for pneumonia increased from 410 per million population in 1997 to 760 in 2002. The pneumonia was community acquired in $289(80 \%)$ and hospital acquired in $72(\mathbf{2 0 \%})$. Hospitalisation for CAP showed a significant seasonal variation with peak admission rates in March and April and the nadir in August and September. The overall mortality rate was $13 \%$, and was significantly higher for HAP (24\%) than for CAP $(10 \%, p<0.01)$. The common microorganisms isolated from sputum culture in CAP were Haemophilus.influenzae $(18.6 \%)$ and Streptococcus.pneumoniae $(10 \%)$. The common pathogen in HAP was Pseudomonas.aeruginosa in $(50 \%)$. 4 out of $17(23 \%) \mathrm{H}$. influenzae isolates were resistant to amoxicillin and 2 of $9 S$. pneumoniae isolates $(22 \%)$ were resistant to penicillin.

Conclusions. The hospitalisation rate for CAP has increased over the years and showed a clear seasonal trend in the UAE. $H$. influenzae was the most common organism among patients with CAP and $P$. aeruginosa in HAP. The mortality rate for HAP was significantly higher than for CAP. The drug resistance pattern was similar to reports from centres elsewhere in South East Asia. Monaldi Arch Chest Dis 2006; 65: 1, 13-18.

Keywords: Community acquired pneumonia, hospital acquired pneumonia, sesonal trends in pneuomonia, pneumococcal pneumonia, drug resistance.

1 Faculty of Medicine \& Health Sciences, Al-Ain,

2 Statistics department, UAE University.

3 Tawam Hospital, Al-Ain, UAE.

Correspondence at current address: Dr. J Joseph MD, FRCP; Associate Professor of Medicine; Pulmonary \& Critical Care Medicine; UCSF Fresno School of Medicine; 445 S. Cedar Ave; Fresno, CA 93702; USA; e-mail: jjoseph@fresno.ucsf.edu

\section{Introduction}

Pneumonia is a common problem worldwide and the reported mortality rate in hospitalised patients varies between 10 and $25 \%$ [1]. The etiological agents in pneumonia show some degree of regional variability [2]. For example a high incidence of Mycoplasma pneumonia infection has been reported in a retrospective analysis by Kurashi et al from Saudi Arabia [3]. An increase in the prevalence of drug resistance to antibiotics among common pathogens has been recognised as a problem in some centres $[4,5]$. Accordingly, local recommendations have been made regarding initial antibiotic choice based on the common pathogens isolated and antimicrobial resistance patterns documented in that community [6]. In this context, there are no published reports from the UAE regarding the hospitalisation rate for patients with pneumonia, the common microorganisms isolated in culture and the prevalence of drug resistance among these pathogens. We therefore retrieved data from hospital records of inpatients over the age of 16 years with a diagnosis of pneumonia admitted to a University Hospital between 1997 and 2002 in order to determine the demographic, clinical and microbiological profile. This will serve as a basis for the rational management of patients with pneumonia in the UAE.

\section{Methods}

Medical records of all patients over the age of 16 years admitted to Tawam hospital, a tertiary referral centre for UAE nationals, between 1997 and 2002 with a diagnosis of pneumonia were identified from a computerised database using International Classification of Diseases code ICD-9-CM. 
The criteria for a diagnosis of community acquired pneumonia (CAP) were symptoms of acute onset cough, fever and a new focal infiltrate on chest radiography with or without isolation of a pathogen from sputum or blood culture. The criteria for hospital-acquired pneumonia (HAP) were any patient who developed symptoms of cough or fever with a new focal infiltrate on chest radiography with or without isolation of a pathogen from sputum or blood culture 3 days or more following admission to hospital. Two independent physicians (JJ, WS) scrutinised patient case records to confirm the diagnosis of pneumonia. A pre-prepared questionnaire was used to collect patients' details which included:

- clinical history;

- vital signs;

- clinical examination findings on admission; and

- the results of the laboratory investigations taken within 24 hours of admission.

Of the 385 admissions, 15 were excluded, as their records did not contain sufficient data for analysis. Furthermore, two patients with a diagnosis of primary lung cancer and seven patients with metastatic lung cancer were excluded. Thus 361 patients were eligible for the final analysis. Mortality from pneumonia was defined as death occurring within 30 days of hospitalisation as a result of pneumonia or resulting from a complication related to the pneumonia. Approval of the study was obtained from the Tawam Hospital and the Faculty of Medicine and Health Sciences Ethics Committee.

\section{Statistical analysis}

Mean values of continuous variables for patients who were alive and dead were compared using an independent sample $t$ test. Mortality rates between patients with CAP and HAP were compared using the Chi square test. Monthly de-trended admission rates of community-acquired pneumonia were plotted against month of the year. De-trending of admission rate was carried out by dividing the admission rate for CAP by the predicted value of the trend based on a multiplicative time series model. All analysis was performed using SPSS version 13.0. A $p$ value of $<0.05$ was considered to be statistically significant.

\section{Results}

Out of the 361 patients studied, 186 were females and 175 males. The mean age \pm SEM for males was $59 \pm 1.6$ years and for females, $56.9 \pm 1.5$ years. Of the total cohort, 247 (68\%) were UAE nationals, 104 (29\%) other Arab nationals, and 10 (3\%) were Asians. The pneumonia was community acquired in $287(80 \%)$ and hospital acquired in $74(20 \%)$. The mean age for CAP was $57 \pm 1.2$ years and for HAP was $58.5 \pm 2.5$ years. The male to female ratio for CAP was 132:155 and for HAP was $43: 31$.

The annual admission rate for CAP increased from 250/100,000 admissions in 1997 to 710/100,000 admissions in 2002 (figure 1). By contrast, the incidence of HAP slowly and steadily, increased until 2000 after which it declined sharply. There was a clear seasonal trend in the admission rate for CAP (figure 2). The peak admission rate occurred in the months of March and April and the nadir was observed in the months of August and September.

Figure 3 provides the details of co-morbidity in CAP and HAP. The common co-morbid risk factors were:

- diabetes in 77 (21\%);

- malignancy in $72(20 \%)$; and

- COPD in $68(19 \%)$.

HIV as a risk factor for pneumonia was present in only 5 patients $(1.4 \%)$. The overall combined mortality rate for pneumonia was $13 \%$. Out of the 47 deaths, 18 were in patients with HAP and 29 in patients with CAP. The mortality rate in the 74 patients with HAP (24\%) was significantly higher compared to the mortality rate in 287 patients $(10 \%)$ with CAP $(\mathrm{p}<0.01)$.

Table 1 shows pertinent clinical information in patients with pneumonia according to whether they survived or died. The mean age (67.2 \pm 2.7$)$ of patients who died was significantly higher than those who survived $(56.4 \pm 1.2)$. The mean systolic blood pressure and pulse oximetry readings were significantly lower in patients who died compared to those who survived (both $\mathrm{p}<0.01$ ). Table 2 shows laboratory test results in this cohort. The mean values for blood urea nitrogen and serum creatinine were significantly higher in patients 


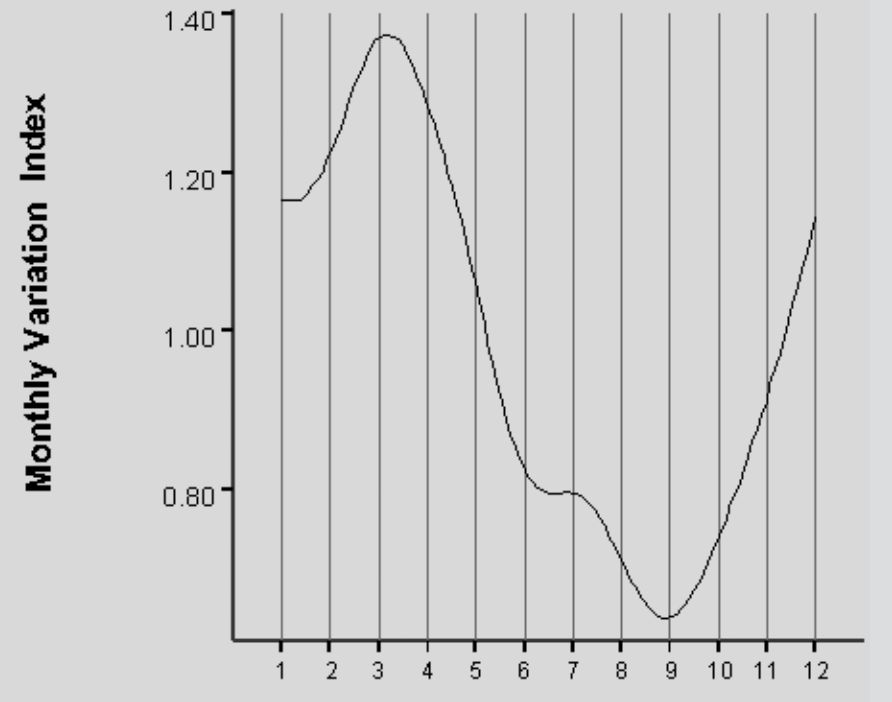

Month of Admission
Fig. 2. - De-trended monthly admission rate for patients with CAP. The peak rate of admission occurred in the months of March and April and the nadir in August and September.



Fig. 3. - Percentage of patients with comorbid factors in CAP and HAP. Some patients had more than one co-morbid risk factor.

who died compared to those who survived $(\mathrm{p}=0.01$ $\& 0.03$ respectively). On blood gas analysis, $\mathrm{PCO}_{2}$ was significantly higher in patients who died $(51.2 \pm 4.8 \mathrm{mmHg})$ compared to those who survived $(37.6 \pm 1.2, \mathrm{p}<0.001)$.

Sputum was processed for bacterial culture within 24 hours of admission in 91 of the 287 patients with CAP and in 22 of the 74 patients with HAP. Table 3 provides the pathogens isolated. The common micro-organisms isolated in patients with CAP were H. influenzae in 17 (18.6\%) and S. pneu- moniae in $9(10 \%)$. There was a predominance of Pseudomonas spp in HAP whereas the most commonly isolated pathogen was $H$. Influenzae in CAP. Furthermore, Candida spp were isolated from sputum in 7 of the 22 patients with HAP and 3 of the 91 patients with CAP.

Although 14 patients had serology testing for Mycoplasma and 5 for Legionella spp, only 4 patients had a titer diagnostic of Mycoplasma pneumoniae and none for Legionella. A blood culture was drawn on admission from 158 patients with CAP, but only 22 patients (14\%) had a pathogen isolated. The organisms isolated in CAP were: $H$. influenzae in 10 patients, S. pneumoniae in 7, Klebsiella spp in 3 and Escherischia coli in 2 patients. Of the 74 patients with HAP, 42 had a blood culture drawn and only $5(8 \%)$ had a pathogen isolated. Reasons for the low yield include prior antibiotic use and a general inadequacy of blood culture technique among physicians, particular in the low volume sampled. The isolates from blood culture were: Pseudomonas spp in 3 patients and Enterobacter spp and Staphylococcus spp in one each. Antibiotic usage prior to hospitalisation was reported in $60 \%$ of all patients. However, as over-the-counter antibiotic use is common in the UAE, this figure is likely to have been underestimated. Table 4 shows the resistance pattern among pathogens isolated on sputum culture. Of the 17 isolates of $H$. influenzae, 4 were resistant to amoxicillin (23\%). Among the nine S. pneumoniae isolates, $2(22 \%)$ were resistant to penicillin and one each to amoxicillin and augmentin respectively.

Of the 361 patients with pneumonia, only $31(9 \%)$ had evidence of pleural effusion on chest radiography. In these 31 patients, 9 underwent thoracocentesis; all nine pleural effusions were exudates and one had empyema which required drainage.

\section{Discussion}

In this retrospective analysis of patients hospitalised for pneumonia in a University Hospital in the UAE, we have documented a steady increase in the admission rate for CAP from 1997 to 2002. While the incidence and the admission rate of CAP has been reported to be declining in some parts of the world [7, 8], an increase in admission rates for CAP in Al Ain, a city within the UAE is evident. Although the total number of patients admitted yearly into this teaching hospital has increased, the admission rate for CAP has been corrected for this variability and therefore represents a true increase in admission 


\begin{tabular}{|c|c|c|c|c|}
\hline Parameter & Outcome & Mean & SEM & $P$ value* \\
\hline \multirow[t]{2}{*}{ Age (years) } & Alive & 56.4 & 1.2 & \multirow[t]{2}{*}{$<0.001$} \\
\hline & Dead & 67.2 & 2.7 & \\
\hline \multirow[t]{2}{*}{ Temperature $\left({ }^{\circ} \mathrm{C}\right)$} & Alive & 37.6 & 0.1 & \multirow[t]{2}{*}{0.21} \\
\hline & Dead & 37.3 & 0.2 & \\
\hline \multirow[t]{2}{*}{ Pulse rate } & Alive & 104.8 & 1.3 & \multirow[t]{2}{*}{0.78} \\
\hline & Dead & 105.8 & 3.9 & \\
\hline \multirow[t]{2}{*}{ Systolic BP (mmHg) } & Alive & 130.0 & 1.5 & \multirow[t]{2}{*}{0.006} \\
\hline & Dead & 117.7 & 4.2 & \\
\hline \multirow[t]{2}{*}{ Diastolic BP (mmHg) } & Alive & 75.1 & 1 & \multirow[t]{2}{*}{0.31} \\
\hline & Dead & 72.3 & 2.5 & \\
\hline \multirow[t]{2}{*}{ Respiratory rate } & Alive & 26.0 & 0.5 & \multirow[t]{2}{*}{0.74} \\
\hline & Dead & 26.4 & 1.5 & \\
\hline \multirow[t]{2}{*}{ Pulse Oxymetry (\%) } & Alive & 92.7 & 0.5 & \multirow[t]{2}{*}{0.009} \\
\hline & Dead & 88.7 & 1.6 & \\
\hline
\end{tabular}

Alive $\mathrm{n}=287$; Dead $\mathrm{n}=74$.

* Statistically Significant by $t$ test.

Table 2. - Laboratory Tests at First Evaluation in Patients with Pneumonia

\begin{tabular}{|c|c|c|c|c|c|}
\hline Laboratory Test & Out-come & Number & Mean & SEM & $P$ value* \\
\hline \multirow[t]{2}{*}{ Total WBC (109/L) } & Alive & 291 & 12.5 & 0.4 & \multirow[t]{2}{*}{0.37} \\
\hline & Dead & 47 & 11.3 & 1.4 & \\
\hline \multirow[t]{2}{*}{ Platelet $(109 / \mathrm{L})$} & Alive & 291 & 292.2 & 8.7 & \multirow[t]{2}{*}{0.27} \\
\hline & Dead & 47 & 265.8 & 26.4 & \\
\hline \multirow{2}{*}{ Blood Urea Nitrogen (mmol/L) } & Alive & 273 & 8.3 & 0.5 & \multirow{2}{*}{0.01} \\
\hline & Dead & 47 & 11.8 & 1.4 & \\
\hline \multirow[t]{2}{*}{ Creatinine (mmol/L) } & Alive & 273 & 93.6 & 3.1 & \multirow[t]{2}{*}{0.03} \\
\hline & Dead & 47 & 112.7 & 11.7 & \\
\hline \multirow[t]{2}{*}{ Sodium (mmol/L) } & Alive & 268 & 136.1 & 0.9 & \multirow[t]{2}{*}{0.32} \\
\hline & Dead & 47 & 138.3 & 1.9 & \\
\hline \multirow[t]{2}{*}{ Glucose (mmol/L) } & Alive & 268 & 9.6 & 0.5 & \multirow[t]{2}{*}{0.77} \\
\hline & Dead & 47 & 9.3 & 0.1 & \\
\hline \multirow[t]{2}{*}{$\mathrm{pH}$} & Alive & 76 & 7.4 & 0.01 & \multirow[t]{2}{*}{0.07} \\
\hline & Dead & 16 & 7.3 & 0.03 & \\
\hline \multirow[t]{2}{*}{$\mathrm{PCO}_{2}(\mathrm{mmHg})$} & Alive & 76 & 37.6 & 1.2 & \multirow[t]{2}{*}{$<0.001$} \\
\hline & Dead & 16 & 51.2 & 4.8 & \\
\hline \multirow[t]{2}{*}{$\mathrm{PO}_{2}(\mathrm{mmHg})$} & Alive & 76 & 64.9 & 3 & \multirow[t]{2}{*}{0.64} \\
\hline & Dead & 16 & 68.3 & 7.2 & \\
\hline
\end{tabular}

* Statistically Significant by $t$ test.

rate for CAP. Whereas we are probably witnessing a true increase in hospitalisation for CAP, change in admission criteria by local physicians might also have contributed since admission was not always based on a rigorous criteria set by the established societies [9].
A clear variation in the monthly admission rate of CAP was observed in our study with the highest admission rates occurring in the months of March and April and the lowest in the months of August and September. Lieberman and associates have documented a similar seasonal variation in Israel 
Table 3. - Sputum Microbiological Profile in Patients with Pneumonia

\begin{tabular}{lccc}
\hline \multirow{2}{*}{$\begin{array}{lcc}\text { Pathogen } \\
\text { Type of Pneumonia }\end{array}$} & \\
\cline { 2 - 3 } & Community & Hospital & \\
\hline E. coli & 3 & 1 & 4 \\
H. influenzae & 17 & 0 & 17 \\
Klebsiella spp. & 2 & 2 & 4 \\
Pseudomonas spp. & 3 & 10 & 13 \\
S. pneumoniae & 9 & 0 & 9 \\
S. aureus & 0 & 2 & 2 \\
Stenotrophomonas spp & 0 & 2 & 2 \\
No significant growth & 55 & 7 & 62 \\
Total & 91 & 22 & 113 \\
\hline
\end{tabular}

$(10,11)$. The city of Al Ain has a population of just over 500,000 and has hot and arid weather conditions from April to October. Temperatures below $20^{\circ} \mathrm{C}$ occur from January till March. Typically, the admission rates for CAP are highest during this period. It appears that the low temperatures may be a trigger factor for the increased incidence of respiratory infections in both northern and southern hemispheres [12-14]. However, what is unique about this community where Tawam hospital is located is that over $70 \%$ of its population is made-up of expatriates from different parts of the world. Typically, there is an exodus of expatiate population yearly during the months of July through August followed by an influx of expatriates back from their country of origin from late August to early September. Interestingly, it is just after the month of September that the admission rate for pneumonia begins to rise. In this context, it is possible that the expatriate population, returning mainly from Asian countries, may play a role in the escalation of hospitalisation rates for pneumonia in this community. Whatever the source of bacteria causing pneumonia in this community, such information regarding the seasonal variation in CAP is helpful in planning vaccination programmes and preparing local hospitals for peak admission rates.
The isolation rate for an etiological agent in our cohort of patients with CAP was low compared to other published series [2, 3, 15-19]. This is partly a result of prior antibiotic use along with failure to use serological testing in the majority of our patients. In our patients with CAP, $H$. Influenzae was the common pathogen. The predominance of $H$. Influenzae as a pathogen may be due to a relatively high mean patient age and the presence of COPD in over $20 \%$ of cases. In contrast to our study, the predominant etiological agents were $S$. pneumoniae and M. pneumoniae in a similar report from Saudi Arabia, although that study was carried out more than a decade ago [3]. Mycoplasma IgM serology was not routinely tested in our patients with CAP. In fourteen patients who had Mycoplasma serology done, only four were reported positive.

The prevalence of penicillin resistant $S$. pneumoniae in our patients with CAP was $22 \%$ although the number of cases is small. Similar figures have been reported from South East Asia and Canada $[4,20]$. The proportion of resistance strains of $H$. influenzae isolates (22\%) from sputum culture against amoxicillin was similar to figures reported by Zhanel and associates in Canada [21]. Surprisingly, only a minority of our patients had pleural effusion and only one developed empyema.

Limitations in our study should be noted. Firstly, as noted above, there was a low rate of a sputum microbiological diagnosis. This reflects, to a large extent, the frequent decision not to send sputum to the microbiology laboratory because of preadmission antibiotic administration. Clearly, education of primary care clinicians regarding the desirability of sputum and blood culture before initiating antibiotic treatment, is needed. Secondly, the cohort of patients studied here consisted largely of local, indigenous Arabs, whereas the majority of non-locals in the region are from South East Asian countries and are admitted to another hospital in the city. At present it is unclear whether the data presented here from the local Arab population also reflects accurately the situation for pneumonia in local expatriates.

In conclusion, while the hospitalisation rate of CAP has increased between 1997 and 2002, the in-

Table 4. - Resistance to common antibiotics among pathogens

\begin{tabular}{|c|c|c|c|c|c|c|}
\hline & $\begin{array}{c}\text { S. pneumoniae } \\
N=9\end{array}$ & $\begin{array}{c}\text { H. influenzae } \\
N=17\end{array}$ & $\begin{array}{c}\text { Klebsiella spp } \\
\quad N=4\end{array}$ & $\begin{array}{c}\text { E. Coli } \\
N=3\end{array}$ & $\begin{array}{c}P . \text { aeruginosa } \\
N=13\end{array}$ & $\begin{array}{c}\text { S. aureus } \\
N=1\end{array}$ \\
\hline Penicillin & 2 & 2 & - & - & - & - \\
\hline TMP/SMX & 2 & 2 & - & 1 & - & 1 \\
\hline Augmentin & 1 & - & & 1 & - & - \\
\hline Amoxycillin & 1 & 4 & 3 & 1 & - & - \\
\hline Ceftriaxone & - & - & - & 1 & - & - \\
\hline Ceftazidine & - & 1 & - & - & 3 & - \\
\hline Gentamicin & - & - & - & - & 1 & - \\
\hline Amikacin & - & - & - & - & 1 & - \\
\hline Piperacillin & - & 2 & - & - & 1 & - \\
\hline Ciprofloxacin & - & - & - & - & - & - \\
\hline
\end{tabular}


cidence of HAP has declined. The overall mortality was $13 \%$. The mortality in patients with HAP was significantly higher compared to those with CAP. There is a clear seasonal trend in the hospitalisation rate in CAP in Al Ain. The frequency of resistance to antibiotics for $S$. pneumoniae and $H$. influenzae appeared to be similar to other reports from South East Asia. A protocol driven prospective study with routine serology for atypical organisms will provide a better understanding of pneumonia in the UAE.

Acknowledgements: We thank the employees of the medical records department of Tawam Hospital for their help with retrieving data and files.

\section{References}

1. Bartlett JG, Mundy LM. Community-acquired pneumonia. $N$ Engl J Med 1995; 333: 1618-1624.

2. Woodhead M. Community-acquired pneumonia in Europe: causative pathogens and resistance patterns. Eur Respir J Suppl 2002; 36: 20s-27s.

3. Kurashi NY, al Hamdan A, Ibrahim EM, et al. Community acquired acute bacterial and atypical pneumonia in Saudi Arabia. Thorax 1992; 47: 115-118.

4. Sangthawan P, Chantaratchada S, Chanthadisai N, Wattanathum A. Prevalence and clinical significance of community-acquired penicillin-resistant pneumococcal pneumonia in Thailand. Respirology 2003; 8: 208-212.

5. Pallares R, Linares J, Vadillo M, et al. Resistance to penicillin and cephalosporin and mortality from severe pneumococcal pneumonia in Barcelona, Spain. $N$ Engl J Med 1995; 333: 474-480.

6. Polk R. Optimal use of modern antibiotics: emerging trends. Clin Infect Dis 1999; 29: 264-274.

7. Ashworth M, Latinovic R, Charlton J, et al. Why has antibiotic prescribing for respiratory illness declined in primary care? A longitudinal study using the General Practice Research Database. J Public Health (Oxf) 2004; 26: 268-274.

8. Fleming DM, Ross AM, Cross KW, Kendall H. The reducing incidence of respiratory tract infection and its relation to antibiotic prescribing. Br J Gen Pract 2003; 53: 778-783.
9. Shah PB, Giudice JC, Griesback R, Jr, et al. The newer guidelines for the management of community-acquired pneumonia. J Am Osteopath Assoc 2004; 104: 521-526.

10. Lieberman D, Lieberman D, Porath A. Seasonal variation in community-acquired pneumonia. Eur Respir $J$ 1996; 9 (12): 2630-2634.

11. Lieberman D, Lieberman D, Friger MD. Seasonal variation in hospital admissions for community-acquired pneumonia: a 5-year study. J Infect 1999; 39: 134-140.

12. Halliday L, Roberts L, Hampson A. Annual report of the National Influenza Surveillance Scheme, 1998. Commun Dis Intell 1999; 23: 185-192.

13. Roche P, Spencer J, Merianos A, Hampson A. Annual report of the National Influenza Surveillance Scheme, 2000. Commun Dis Intell 2001; 25: 107-112.

14. Saynajakangas P, Keistinen T, Tuuponen T. Seasonal fluctuations in hospitalisation for pneumonia in Finland. Int J Circumpolar Health 2001; 60: 34-40.

15. Lim WS, Macfarlane JT, Boswell TC, et al. Study of community acquired pneumonia aetiology (SCAPA) in adults admitted to hospital: implications for management guidelines. Thorax 2001; 56: 296-301.

16. Lieberman D, Schlaeffer F, Lieberman D, et al. Mycoplasma pneumoniae community-acquired pneumonia: a review of 101 hospitalized adult patients. Respiration 1996; 63: 261-266.

17. Howard LS, Sillis M, Pasteur MC, et al. Microbiological profile of community-acquired pneumonia in adults over the last 20 years. $J$ Infect 2005; 50: 107-113.

18. Wattanathum A, Chaoprasong C, Nunthapisud P, et al. Community-acquired pneumonia in southeast Asia: the microbial differences between ambulatory and hospitalized patients. Chest 2003; 123: 1512-1519.

19. Lieberman D, Schlaeffer F, Boldur I, et al. Multiple pathogens in adult patients admitted with communityacquired pneumonia: a one year prospective study of 346 consecutive patients. Thorax 1996; 51: 179-184.

20. Zhanel GG, Palatnick L, Nichol KA, et al. Antimicrobial resistance in respiratory tract Streptococcus pneumoniae isolates: results of the Canadian Respiratory Organism Susceptibility Study, 1997 to 2002. Antimicrob Agents Chemother 2003; 47: 1867-1874.

21. Zhanel GG, Palatnick L, Nichol KA, et al. Antimicrobial resistance in Haemophilus influenzae and Moraxella catarrhalis respiratory tract isolates: results of the Canadian Respiratory Organism Susceptibility Study, 1997 to 2002. Antimicrob Agents Chemother 2003; 47: 1875-1881.

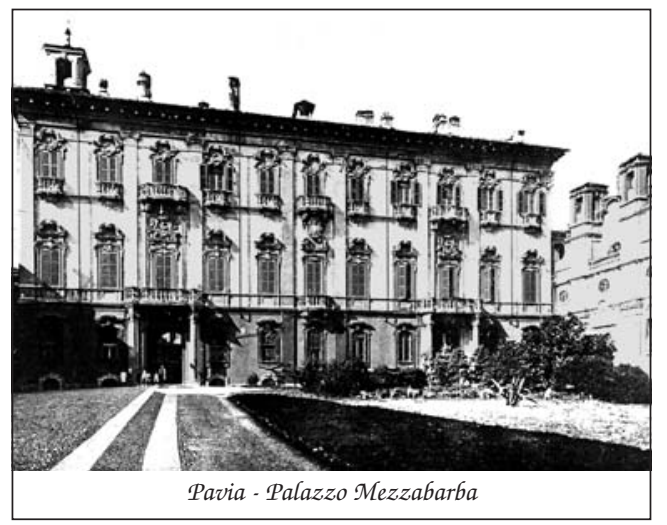

